DOI: http://dx.doi.org/10.33846/hn41008

http://heanoti.com/index.php/hn

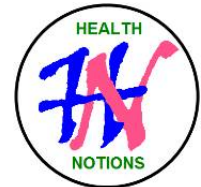

RESEARCH ARTICLE

URL of this article: http://heanoti.com/index.php/hn/article/view/hn41008

\title{
Correlation Between The History of Previous Lower Extremity Amputation as a Risk Factor for the Subsequent Lower Extremity Amputation in Diabetic Patients Among RSUD Dr. Soetomo Patients in 2018
}

\author{
Mochamad Wildan ${ }^{1(\mathrm{CA})}$, Sony Wibisono ${ }^{2}$, Heroe Soebroto ${ }^{3}$ \\ ${ }^{1(\mathrm{CA})}$ Faculty of Medicine, Universitas Airlangga, Indonesia; mochamadwildan97@ gmail.com (Corresponding Author) \\ ${ }^{2}$ Internal Medicine Department, Faculty of Medicine, Universitas Airlangga, Indonesia; \\ sonywibisono@yahoo.com \\ ${ }^{3}$ Cardiovascular Thoracic Surgery Department, Faculty of Medicine, Universitas Airlangga, Indonesia; \\ heroesurgeon@yahoo.com
}

\begin{abstract}
Diabetes mellitus is a group of metabolic diseases characterized by hyperglycemia. Complications are common among patients with this condition, such as diabetic foot syndrome, which is the presence of foot ulcer associated with neuropathy, PAD, and infection, and is a major cause of LEA. Aim of this research is to analyze the correlation between previous LEA as a risk factor for the subsequent LEA in patients with Diabetic Foot among patients in RSUD Dr. Soetomo, Surabaya from January-December 2018. This is descriptive crosssectional study. Data was analyzed using descriptive statistic and correlation test with Microsoft Excel 2007 and SPSS 20. Statistical testing was performed using Spearman's rank correlation and Cohen J criteria with significance level of $\mathrm{P}<0.01$. There are 45 patients, $54.3 \%$ are male and and $45.7 \%$ are female. Largest age group is $>55$ years old $(62.9 \%)$. Mostly have undergone LEA $(74.3 \%)$ while the remaining have undergone LEA twice $(17.1 \%)$. There is a significant correlation between initial LEA and the subsequent LEA $(\mathrm{p}<0.01)$ and is found to have a large correlation between the variables shown by the correlation coefficient (.634). There is no significant correlation between age and LEA as well as sex and LEA ( $p>0.01)$.
\end{abstract}

Keywords: diabetes mellitus; lower extremity amputation; risk factors; RSUD Dr. Soetomo

\section{INTRODUCTION}

Diabetes mellitus is a group of metabolic diseases characterized by hyperglycemia resulting from defects in insulin secretion ${ }^{(1)}$. Diabetes complications are common among patients with T1DM or T2DM but, at the same time, are responsible for significant morbidity and mortality, such as diabetic foot syndrome which is a condition that has been defined as the presence of foot ulcer associated with neuropathy, PAD, and infection, and is a major cause of lower limb amputation ${ }^{(2)}$.

Diabetic foot ulcers (DFU) are common and estimated to affect $15 \%$ of all diabetic individuals during their lifetime. It is now appreciated that $15-20 \%$ of patients with such foot ulcers go on to need an amputation ${ }^{(3)}$. DFU may cause significant morbidity and if not treated aggressively, may lead to lower extremity amputation (LEA). Majority of DFU will heal, whereas $10-15 \%$ of them will remain active, and up to $24 \%$ of them will lead to LEA. There are various risk factors that would lead in invidual into needing to undergo LEA and having underwent LEA previously is one of them alongside with many others, such as poor treatment and poor prevention of diabetic foot ${ }^{(4)}$.

\section{METHODS}

This was descriptive cross-sectional study. Data was analyzed using descriptive statistic and correlation test with Microsoft Excel 2007 and SPSS 20. Statistical testing was performed using Spearman's rank correlation and Cohen $\mathrm{J}$ criteria with significance level of $\mathrm{P}<0.01$. Ethical clearance was granted by KEPK RSUD Dr. Soetomo, Surabaya No. 2021/KEPK/VI/2020. 


\section{RESULTS}

Based on the table 1, it can observed that the mean age of the subjects is 59.5 years old with an SD of \pm 10.4. Number of male subjects involved in the study is higher (19 subjects or $54.3 \%$ ) than that of the female ones $(16$ or $45.7 \%$ ). Most of the patients involved in this study are aged $>55$ years old (22 subjects or $63 \%$ ) whereas patients aged $<55$ years old amounted to be the minority $(13$ subjects or $37 \%)$.

Table 1. Age and sex of research subjects

\begin{tabular}{ccccc}
\hline Variables & \multicolumn{2}{c}{ Sex } & \multicolumn{2}{c}{ Total, $\mathrm{n}=35$} \\
\hline Age $^{1.2}$ & Male & Female & $\mathrm{n}$ & $\%$ \\
\hline$<55$ years old & 6 & 7 & 13 & 37 \\
\hline$>55$ years old & 13 & 9 & 22 & 63 \\
\hline
\end{tabular}

${ }^{1}$ Minimum age: 40 years old; maximum age: 78 years old; ${ }^{2}$ Mean \pm SD: $59.5 \pm 10.4$

Based on the table 2, the significant value (.891) is higher than the P-value (0.01), which means that there is no significant correlation between the variable of Age and Lower Extremity Amputation. Aside from that, the correlation coefficient $(-0.24)$ is negative, which means that the variables are in non-linear correlation. Of all subjects with Type 2 Diabetes Mellitus (T2DM), most of them (32 or 91.4\%) have underwent amputation whereas only a small portion of them did not go undergo amputation ( 3 or $8.6 \%$ ) since they are only required to undergo a more minor intervention, such as debridement, thrombectomy or necrotomy.

Table 2. Correlation between age and lower extremity ampuation

\begin{tabular}{|c|c|c|c|c|}
\hline Variables & \multicolumn{2}{|c|}{ Age } & \multicolumn{2}{|c|}{ Total, $\mathrm{n}=35$} \\
\hline LEA & $<55$ Years Old & $<55$ Years Old & $\mathrm{N}$ & $\%$ \\
\hline No history of LEA & 1 & 2 & 3 & 9 \\
\hline History of LEA & 12 & 20 & 32 & 91 \\
\hline Correlation coefficie & $=-0.024^{* * 3}$ & $\mathrm{e}^{2}=0.891$ & & \\
\hline
\end{tabular}

Based on the table 3, the significant value (.102) is higher than the p-value $(0.01)$, which means that there is no significant correlation between the variables of Sex and Lower Extremity Amputation. Aside from that, the correlation coefficient $(-0.281)$ is negative, which means that the variables are in non-linear correlation.

Table 3. Correlation between sex and lower extremity ampuation

\begin{tabular}{|c|c|c|c|c|}
\hline \multirow{2}{*}{$\begin{array}{c}\text { Variables } \\
\text { LEA }\end{array}$} & \multicolumn{2}{|c|}{ Sex } & \multicolumn{2}{|c|}{ Total, $n=35$} \\
\hline & Male & Female & $\mathrm{N}$ & $\%$ \\
\hline No history of LEA & 3 & 0 & 3 & 9 \\
\hline History of LEA & 16 & 16 & 32 & 91 \\
\hline $\begin{array}{l}\text { Correlation coeffici } \\
\text { P-value }^{2}=.102\end{array}$ & $31^{* * 3}$ & & & \\
\hline
\end{tabular}

Based on the table 4, the correlation coefficient $\left(.634^{* *}\right)$ is interpreted as having large correlation on the variables compared, which in this case would be Lower Extremity Amputation and Subsequent Lower Extremity Amputation. Aside from that, the correlation coefficient is positive $\left(.245^{* *}\right)$, which means that the variables are in linear correlation. As for the significant value (.000), is lower than P-value (0.01). This value goes to show that there is a significant correlation between Lower Extremity Amputation and the Subsequent Lower Extremity Amputation and it is considered to be a large correlation present between these two variables. From those subjects whom have undergone amputation, a minority (6 or 17.1\%) have experienced two Lower Extremity Amputations (LEA) whereas the majority have only experienced one LEA. 
Table 4. Correlation between sex and lower extremity ampuation

\begin{tabular}{|c|c|c|c|c|c|}
\hline Variables & \multicolumn{3}{|c|}{ Subsequent LEA } & \multicolumn{2}{|c|}{ Total, $\mathrm{n}=35$} \\
\hline LEA & No History of LEA & History of LEA once & History of LEA twice & $\mathrm{n}$ & $\%$ \\
\hline $\begin{array}{l}\text { No History of } \\
\text { LEA }\end{array}$ & 3 & 0 & 0 & 3 & 9 \\
\hline History of LEA & 0 & 26 & 6 & 32 & 91 \\
\hline Correlation Coeff & $\mathrm{t}^{1}=0.634$ & $=0.000^{* * 3}$ & & & \\
\hline
\end{tabular}

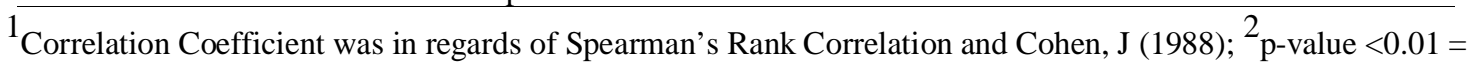
significant; ${ }^{3} * *$.Correlation is significant at the 0.01 level (2-tailed)

\section{DISCUSSION}

\section{Individual Characteristics of Research Subjects}

Reasoning behind as for why the feet of diabetic patients are at risk for experiencing a large spectrum of conditions are due to what is called diabetic foot syndrome (DFS). A study reported that patients aged $>55$ years old is more prone to suffer from this condition ${ }^{(5)}$. Broad spectrum of risk factors leading to major LEA which are related to DFS have been reported, some of which are peripheral artery disease (PAD), associated cardiovascular comorbidities and old age ${ }^{(6)}$. Hence, from these studies, it may be said that patients who are suffering from diabetic foot aged above 55 years old are more prone to undergo LEA as management. For the gender group, it is thought that men are more susceptible in undergoing LEA due to diabetic foot conditition, reasoning for this is due to men are more likely to experience diseases that directly link to formation of the risk factors of LEA, such as DFU, PAD, cigarette use, and peripheral neuropathy. Aside from that, women have better endothelial function since they have additional neural protection which plays part in micro and microvasculature. Not only that, men are also more prone to experience decrease in joint mobility and having higher foot pressure ${ }^{(7)}$. Hence, these facts lead men to be more susceptible in formation of DFU and hence, making men more susceptible in having conditions that is related to diabetes related LEA. Conditions such as decreased ankle brachial index (ABI) and transcutaneous ocygen pressure have been proven to be a vital role in predicting whether a patient whom has undergone LEA to be in the risk of undergoing the subsequent LEA. It is thought that almost $70 \%$ of hospital readmissions following an amputation, which typically requires reamputation as the treatment is caused by infection or a non-healing wound following initial amputation. Patients with initial amputation to the level of digital amputation were the treatment to almost $58 \%$ of reamputation $^{(8)}$.

\section{Correlation between Age and Lower Extremity Amputation}

A study which was done to rule out risk factors for LEA in T2DM patients showed results that mainly the comorbidities that is present in patients whom eventually will lead to undergo amputations are first, the level of $\mathrm{HbA1c}$, their duration of T2DM, what kind of antidiabetic treatments they are on, presence of chronic kidney disease (CKD). As for foot characteristics, it is shown that those who experience ischemia of the foot and have higher Wagner grade are at higher risk of LEA ${ }^{(5)}$. However, when speaking of age, the study showed no significant correlation between old age and the need for LEA with condition of T2DM although majority of the patients that participated are aged above 55 years old. Similar with this study, although most of the subject are aged above 55 years old $(62.9 \%)$, it showed no significant correlation between age and LEA ( $<<0.891)$.

\section{Correlation between Sex and Lower Extremity Amputation}

In a study that involved $5325 \mathrm{~T} 2 \mathrm{DM}$ patients whom have undergone LEA, most of them happens to be male $(72.54 \%)^{(9)}$. Another study supports this stand, among 572 diabetic patients, of 21 whom underwent LEA, most of them $(52.4 \%)$ are found to be male. Not only that, it also showed that men were more likely to undergo T2DM related LEA as compared to women $(\mathrm{p}<0.0083)^{(10)}$. These claims from the result of the studies above may be supported by the fact that there are difference in behaviour when it comes to footcare with different gender, such as women are more likely to undergo prophylaxis foot care ${ }^{(11)}$. Another hypothesis that may support the stand would be men are more likely to neglect health status and care, not only that, men are also thought to be under constant pressure from their surroundings regarding expectations of having to be constantly fit and vigorous at all times ${ }^{(12)}$. In contrary, the result of this study showed the otherwise. Although majority of the subjects are male $(54.3 \%)$, there is no significant correlation between sex and LEA in this $\operatorname{study}(\mathrm{p}<0.12)$.

\section{Correlation between Lower Extremity Amputation and Subsequent Lower Extremity Amputation}

In a study which focused on ruling the predictors for hospital readmissions as well as reamputation following LEA, it was found that among 717 patients whom undergone LEA, readmission occurred in $13.9 \%$ 
and from $95 \%$ of those readmitted required reamputations ${ }^{(8)}$. This finding is then supported by another study which concluded that T2DM patients with comorbidity of hypertension, congestive heart failure, and chronic obstructive pulmonary disorder, have increased risk of up to $21 \%$ into being readmitted following LEA, whereby most of the actions taken needed following readmission would be the subsequent LEA ${ }^{(13)}$. Aside from the comorbidities mentioned, decreased ABI as well as transcutaneous oxygen pressure following LEA is established to be a prediction of poor wound healing, hence making it able to be a parameter of whether a patient whom undergone LEA will have the risk of undergoing the subsequent LEA ${ }^{(14)}$. Similar to the result of this study, it showed that there is a significant correlation between LEA and the subsequent LEA $(\mathrm{p}<0.000)$. Not only that, it is also found that there is a large correlation shown by correlation coefficient (.634) in accordance to the correlation grouping $\operatorname{rank}^{(15)}$.

\section{CONCLUSION}

There is no significant correlation between age and LEA as well as sex and LEA, however there is a significant correlation between LEA and the subsequent LEA and is considered as a large correlation. From this study, it is suggested that people suffering from T2DM to go for regular check ups to nearest healthcare facilty to be aware about the health status in order to prevent the condition from progressing to a worse stage, as well as have high compliance towards the therapy regiments by consuming the medicine given properly and lead a healthier lifestyle.

\section{REFERENCES}

1. Kharroubi A. Diabetes mellitus: The epidemic of the century. World Journal of Diabetes. 2015;6(6):850.

2. Papatheodorou K, Banach M, Bekiari E, Rizzo M, Edmonds M. Complications of Diabetes 2017. Journal of Diabetes Research. 2018;2018:1-4.

3. Pendsey S. Understanding diabetic foot. International Journal of Diabetes in Developing Countries. 2010;30(2):75.

4. Pemayun T, Naibaho R, Novitasari D, Amin N, Minuljo T. Risk factors for lower extremity amputation in patients with diabetic foot ulcers: a hospital-based case-control study. Diabetic Foot \& Ankle. 2015;6(1):29629.

5. Shatnawi N, Al-Zoubi N, Hawamdeh H, Khader Y, Gharaibeh K, Heis H. Predictors of major lower limb amputation in type 2 diabetic patients referred for hospital care with diabetic foot syndrome. Diabetes, Metabolic Syndrome and Obesity: Targets and Therapy. 2018;Volume 11:313-319.

6. Pscherer S, Dippel F, Lauterbach S, Kostev K. Amputation rate and risk factors in type 2 patients with diabetic foot syndrome under real-life conditions in Germany. Primary Care Diabetes. 2012;6(3):241-246.

7. Peek M. Gender Differences in Diabetes-related Lower Extremity Amputations. Clinical Orthopaedics and Related Research®. 2010;469(7):1951-1955.

8. Beaulieu R, Grimm J, Lyu H, Abularrage C, Perler B. Rates and predictors of readmission after minor lower extremity amputations. Journal of Vascular Surgery. 2015;62(1):101-105.

9. López-de-Andrés A, Jiménez-García R, Esteban-Vasallo M, Hernández-Barrera V, Aragon-Sánchez J, Jiménez-Trujillo I et al. Time Trends in the Incidence of Long-Term Mortality in T2DM Patients Who Have Undergone a Lower Extremity Amputation. Results of a Descriptive and Retrospective Cohort Study. Journal of Clinical Medicine. 2019;8(10):1597.

10. Laclé A, Valero-Juan L. Diabetes-related lower-extremity amputation incidence and risk factors: a prospective seven-year study in Costa Rica. Revista Panamericana de Salud Pública. 2012;32(3):192-198.

11. Bruun C, Siersma V, Guassora A, Holstein P, de Fine Olivarius N. Amputations and foot ulcers in patients newly diagnosed with Type 2 diabetes mellitus and observed for 19 years. The role of age, gender and comorbidity. Diabetic Medicine. 2013;30(8):964-972.

12. Shin J, Roh S, Lee N, Yang K. Influence of Epidemiologic and Patient Behavior-Related Predictors on Amputation Rates in Diabetic Patients. The International Journal of Lower Extremity Wounds. 2017;16(1):14-22.

13. van Walraven C, Dhalla I, Bell C, Etchells E, Stiell I, Zarnke K et al. Derivation and validation of an index to predict early death or unplanned readmission after discharge from hospital to the community. Canadian Medical Association Journal. 2010;182(6):551-557.

14. Andrews K, Dib M, Shives T, Hoskin T, Liedl D, Boon A. Noninvasive Arterial Studies Including Transcutaneous Oxygen Pressure Measurements with the Limbs Elevated or Dependent to Predict Healing After Partial Foot Amputation. American Journal of Physical Medicine \& Rehabilitation. 2013;92(5):385392.

15. Cohen J. Statistical power analysis for the behavioral sciences. 2nd ed. Hove: Lawrence Erlbaum Associates; 1988. 